\title{
Successful Catheter Ablation of a Right-Sided Accessory Pathway in a Child With Interruption of the Inferior Vena Cava and Azygos Continuation
}

\author{
Ayhan KILIC, ${ }^{1}$ MD, Basri Amasyali, ${ }^{1} \mathrm{MD}$, Sedat Kose, ${ }^{1} \mathrm{MD}$, \\ Kudret AYTEMIR, ${ }^{1}$ MD Hurkan KursaKLIOGLU, ${ }^{1}$ MD, \\ and Mustafa K. LENK, ${ }^{1} \mathrm{MD}$
}

\begin{abstract}
SUMMARY
Azygos continuation is seen in $0.6 \%$ of patients with congenital heart disease. The major significance of this anomaly lies in its association with complex cardiac defects and the technical difficulty that can accompany cardiac catheterization. We report our experience with successful catheter ablation of a right posteroseptal concealed accessory pathway in a 6-year-old boy with infrahepatic interruption of the inferior vena cava and azygos continuation. (Int Heart J 2005; 46: 537-541)
\end{abstract}

Key words: Azygos continuation, Accessory pathway, Ablation

USE of radiofrequency catheter ablation (RFCA) in the treatment of supraventricular tachycardias (SVT), as well as its success and complication rates, is influenced by the presence of congenital anomalies. We wish to share our experience with successful catheter ablation of a right posteroseptal concealed accessory pathway (AP) in a 6-year-old boy with infrahepatic interruption of the inferior vena cava (IVC) and azygos continuation. To the best of our knowledge, catheter ablation has not yet been reported in this anomaly.

\section{CASE REPORT}

A 6-year-old boy was admitted because of palpitations and dizziness. His history revealed that the palpitations had started two years earlier, recurred 2-3 times a year, lasted 1-3 hours, and started and ended abruptly.

His body weight and height were $21 \mathrm{~kg}$ and $115 \mathrm{~cm}\left(50^{\text {th }}\right.$ centile for both $)$, respectively. A physical examination was normal. A 12-lead surface ECG showed sinus rhythm, with no signs of abnormal conduction or impulse genera-

From the ${ }^{1}$ Department of Pediatric Cardiology, Gulhane Military Medical Academy, Ankara, Turkey.

Address for correspondence: Ayhan Kilic, MD, Department of Pediatrics, Gulhane Military Medical Academy, 06018, Ankara, Turkey.

Received for publication August 19, 2004

Revised and accepted February 7, 2005. 
tion. The cardiac shadow and vascular marks on the chest radiogram were normal; however, there was a distinctive shadow of an enlarged vessel in the region of the superior vena cava. Echocardiography revealed that the inferior vena cava was interrupted at the infrahepatic level, the hepatic veins were opening directly into the right atrium, and the systemic venous return from the lower half of the body was draining into the superior vena cava through an enlarged azygos vein (Figure 1). The atrial and ventricular situs were normal; the great arteries were normally aligned with their respective cardiac chambers. Abdominal ultrasonography was normal; selective splenic scintigraphy excluded polysplenia. An invasive electrophysiological study, and catheter ablation in the same session if necessary and applicable, was planned.

The patient was transferred to the cardiac catheterization laboratory, fasting and sedated with midazolam. Three electrode catheters, two 6-French Josephson catheters, and one 7-French ablation catheter (Medtronic, Minneapolis, MN), were advanced through both femoral veins and placed at high right atrium (HRA), His-right ventricular apex, and coronary sinus (CS) positions. The course of the catheters, which ran smoothly up into the superior vena cava and then into the right atrium from above, confirmed the anatomic diagnosis. This diagnosis was further supported by injection of contrast material in the posteroanterior and lateral projections (Figure 2).

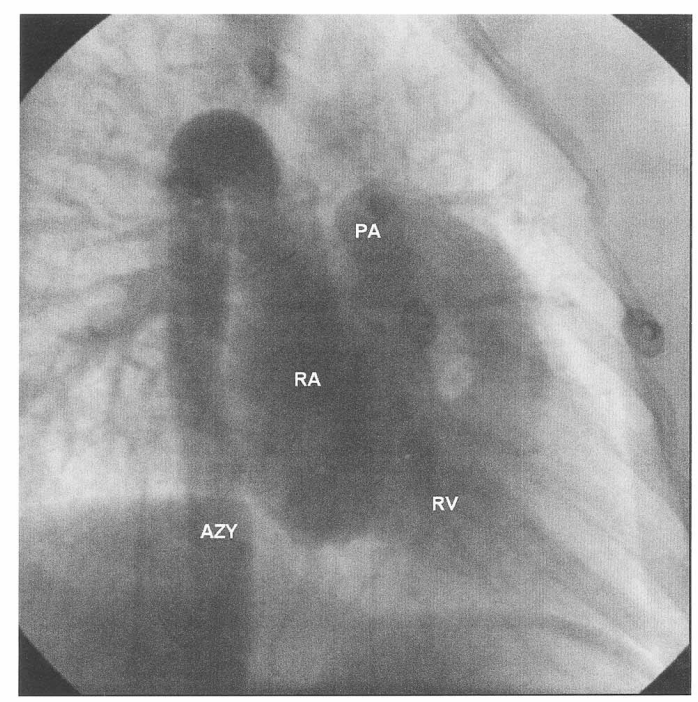

Figure 1. Right anterior oblique view with contrast injection showing the course of the azygos vein and its connection to the right atrium. Note that the right ventricle and the main pulmonary artery are located normally. AZY = azygos vein; $\mathrm{RA}=$ right atrium; $\mathrm{RV}=$ right ventricle; $\mathrm{PA}=$ main pulmonary artery. 


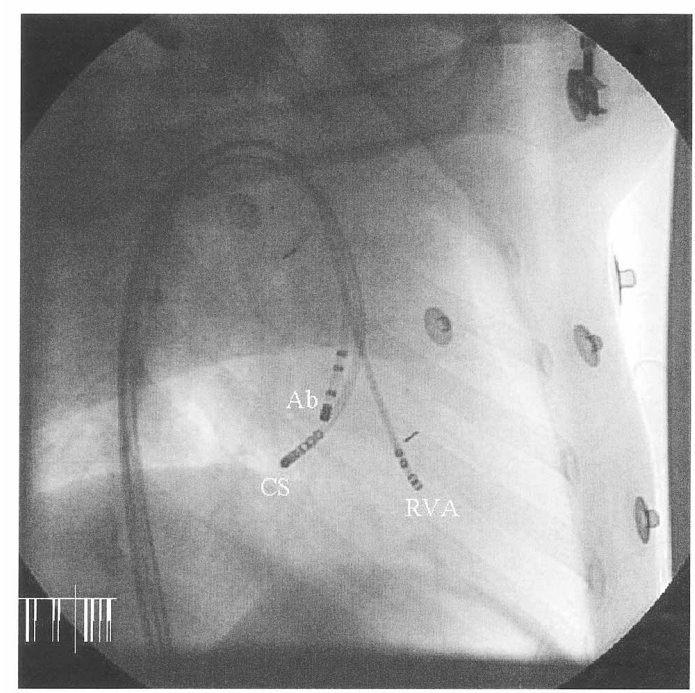

Figure 2. Right anterior oblique view of the course and intracardiac locations of the catheters at successful site of ablation. $\mathrm{CS}=$ coronary sinus; $\mathrm{Ab}=$ ablation; RVA = right ventricular apex.

During electrophysiological study, basal measurements were within normal ranges for his age. Programmed atrial stimulation showed a smooth AV conduction curve with no signs of dual AV node physiology. An orthodromic tachycardia was reproducibly induced with programmed atrial stimulation. During SVT, the ventriculoatrial (VA) conduction interval recorded from the HRA catheter was $130 \mathrm{msec}$ and the earliest retrograde atrial activation was localized to the proximal electrode pair of the CS catheter. Ventricular extrastimuli, given from the right ventricle at progressively shortened coupling intervals when the His bundle was refractory, reproducibly advanced the next atrial activation, thus excluding the possibility of atypical AV reentrant tachycardia and atrial tachycardia originating from the posteroseptal region. Then, the SVT was stopped with incremental pacing and retrograde activation patterns were examined. The retrograde atrial activation pattern during programmed ventricular pacing was the same as that during SVT and was not decremental.

Based on these findings, a diagnosis of orthodromic atrioventricular reciprocating tachycardia was made. The tricuspid annulus was mapped to detect an AP potential, the shortest VA interval, or retrograde continuous activation. With application of temperature-controlled radiofrequency energy, set at $60^{\circ} \mathrm{C}$ and 50 


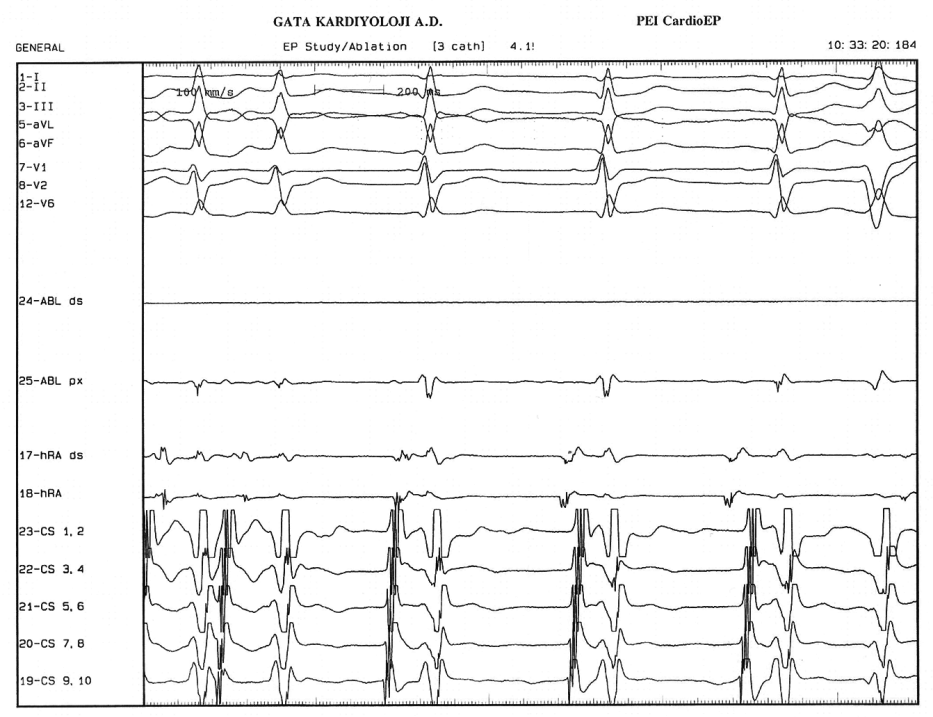

Figure 3. Intracardiac electrogram at time of successful catheter ablation. $h R A=$ high right atrium; $\mathrm{ABL}=$ ablation; $\mathrm{CS}=$ coronary sinus .

Watts, at a site close to the CS ostium, the tachycardia was stopped at the retrograde limb (Figure 3). Ventricular pacing confirmed elimination of the AP conduction and dissociation of VA conduction. No tachycardia was inducible after the procedure. The total procedure duration was 75 minutes and the fluoroscopy time was 25 minutes.

\section{DISCUSSION}

The most common form of abnormal tachycardias in childhood is SVT, 73\% of which is due to APs. ${ }^{1)}$ The treatment of choice in SVT causing hemodynamic disturbances is RF ablation. Delineation of the anatomy and, if abnormal, planning the procedure accordingly is mandatory.

The most common anomaly involving the inferior vena cava is absence of its infrahepatic segment and connection to the superior vena cava through the azygos vein. ${ }^{2}$ Azygos continuation is seen in $0.6 \%$ of patients with congenital heart disease. ${ }^{3)}$ It is frequently associated with complex cyanotic lesions and bears a strong association with left isomerism (polysplenia syndrome). ${ }^{4)}$ The enlarged vein, as is in our case, may be visible in a frontal chest radiograph as a prominent rounded structure of water density in the right upper perihilar region. 
The diagnosis is easily made with cross-sectional echocardiography. ${ }^{5)}$ The presence of this anomaly makes cardiac catheterization from the lower extremity extremely more difficult. The major significance of this anomaly lies in its association with complex cardiac defects and the technical difficulty that can accompany cardiac catheterization. ${ }^{2)}$ Kler, et al have reported catheter ablation of a leftsided accessory pathway in a patient with interruption of IVC. ${ }^{6}$ ) To our knowledge, catheter ablation of a right-sided accessory pathway in a patient with interruption of IVC and hemiazygos continuation has not yet been reported.

Advancement of three catheters, the minimum number of catheters required in this situation, was accomplished with difficulty because of the relative narrowing at the junction of the SVC, azygos vein, and the right atrium. Besides this, manipulation of the catheters, especially of the mapping and ablation catheter, was difficult and time-consuming. Catheterization of the coronary sinus, however, was accomplished with ease and took less time than anticipated, as would be expected in the jugular venous approach.

In conclusion, we report a case with SVT, infrahepatic interruption of the IVC, and azygos continuation, treated successfully with RFCA. The use of smaller caliber diagnostic catheters could have significantly facilitated the procedure.

\section{REFERENCES}

1. Ko JK, Deal BJ, Strasburger JF, Benson DW Jr. Supraventricular tachycardia mechanisms and their age distribution in pediatric patients. Am J Cardiol 1992; 69: 1028-32.

2. Fischer DR, Zuberbuhler JR. Anomalous systemic venous venous return. In RH Anderson, et al, eds. Paediatric Cardiology, Volume 1. Edinburgh, Churchill Livingstone; 2002: 851-66.

3. Anderson RC, Adams P Jr., Burke B. Anomalous inferior vena cava with azygos continuation (infrahepatic interruption of the inferior vena cava). Report of 15 new cases. J Pediatr 1961; 59: 370-83.

4. Sharma S, Devine W, Anderson RH, Zuberbuhler JR. Identification and analysis of left atrial isomerism. Am J Cardiol 1987; 60: 1157-60.

5. Huhta JC, Smallhorn JF, Macartney FJ. Cross-sectional echocardiographic diagnosis of azygos continuation of the inferior vena cava. Cathet Cardiovasc Diagn 1984; 10: 221-32.

6. Kler TS, Bhatia A, Saxena A, Sardana R, Arora V. Catheter ablation of left free wall accessory pathway in a patient with inferior vena cava interruption. Indian Heart J 2002; 54: 705-7. 